\title{
CRITICAL M OM ENTS OF (UN)DOING DOCTORAL SUPERVISION: COLLABORATIVE WRITING AS RHIZOMATIC PRACTICE
}

\author{
SIMONE FULLAGAR \\ s.p.fullagar@bath.ac.uk \\ University of Bath \\ ADELE PAVLIDIS \\ a.pavlidis@griffith.edu.au \\ Griffith University \\ RAPHAELA STADLER \\ r.stadler@herts.ac.uk \\ University of Hertfordshire
}

\begin{abstract}
Despite the proliferation of doctoral training courses within universities, little attention is paid to the complexity of supervision as a process of becoming for both students and supervisors. As post-qualitative researchers we explore how collaborative writing can be mobilised as a rhizomatic practice to open up engagements with supervision that counter hierarchical master/apprentice models of knowledge transmission. Researching-writing through our own knowledge practices and affective investments we engage with supervision as an assemblage that produces multiplicity. We created a democratic learning alliance through an electronic writing forum. These collaborative e-writing practices generated insights into, and movements through, critical moments that disrupted the doctoral experience of progress (writers block, self-doubt, misunderstanding). We theorise collaborative writing as a rhizomatic practice that refuses ontological assumptions of linearity, causality and rationality, instead following the embodied lines of thought, affective intensities and problematics that haunt the supervision relationship. We recast supervision as an improvisation through which academic dilemmas/possibilities are negotiated and performed anew.
\end{abstract}

Keywords: doctoral supervision; post-qualitative inquiry; Deleuze; collaborative writing; rhizomatic practice 


\section{Introduction}

It was as if you did this [supervision] by a kind of divine aura around you as a scholar, and the student would stand close and get warmed by this. (Connell \& Manathunga, 2012, p. 5)

When read together this opening quotation by Connell and Manathunga reveal the mystique that traditionally enveloped the $\mathrm{PhD}$ supervisor and student in a shroud of hierarchical, transcendent knowledge relations. Connell and Manathunga, (2012, p. 5) go on to make the point that current supervisory approaches that have embraced a more 'technical-rational' approach are equally problematic in misunderstanding the complexity of this particular pedagogical relationship. Through our postqualitative inquiry (Lather \& St Pierre, 2013; St Pierre, 2012) this article explores the dilemmas of doctoral supervision in the desire to create different knowledge practices, movements and ethical relations through our entangled experiences as supervisor (SF) and students (RS \& AP). We critique the dualisms of mystical/ technical solutions, reason/emotion, self-certainty/other-dependence, master/ apprentice hierarchies. We develop an alternative, rhizomatic knowledge practice collaborative writing - as a generative process for becoming researchers (studentssupervisors) (Claiborne, 2013; Gannon, 2006; Wyatt, Gale, Gannon \& Davies, 2010). Kuby et al., (2016, p. 142) suggest that 'The rhizome is a metaphoric tool that helps us to consider the ways teaching $\leftrightarrow$ learning shoot-off in unpredictable directions and take instructors/students to new territories.'

We aim to contribute to the growing body of critical scholarship on doctoral pedagogy through our individual and shared writing voice/s to articulate ways of moving through supervision dilemmas (Benade, 2015; Halse \& Bansel, 2012; Manathunga \& Goozée, 2007). These voices are, as Mazzei (2013, p. 735) suggests, ' $\ldots$ an entanglement of desires, intensities, and flows' produced in collaborative writing exchanges during the doctoral process and post-graduation for the second and third authors (Fox \& Allan, 2014). Lenz Taguchi's (2013) exploration of the micropolitics of collaborative writing within doctoral coursework also points towards the intensification of the 'self-management' discourse within the Australian-New Zealand-British context where social science/humanities students are engaged solely in research without course work. Collaborative writing has enabled us to make visible several key moments of doing/undoing the performance of supervisory relations and challenge the culture of silence that impedes creative engagement (Benade, 2015; Freire, 1998). Our writing explores several key moments, i) the affects of 'not knowing', ii) (un)learning and improvising practices, iii) unexpected material relations and iv) becoming-improvising supervisors through an assemblage of affects, norms and desires that shape academic practices. Although these accounts are written as distinct autoethnographic fragments they are connected by affective traces that constitute the assemblage of our analytic conversations around critical moments and shared insights. We write through the voices of 'I' and 'we' not in order to 'represent' our personalised accounts, but in 
Deleuze and Guattari's (1987) sense to produce multiplicities that disturb the normalised power relations that govern the pedagogic relation between students and supervisors. Against the continual territorialisation of doctoral supervision by normalised practices that reassert supervisor/student dualisms, we trace the deterritorialising effects of collaborative writing that intervenes to open up ways of inhabiting the 'in-between' spaces. Wyatt et al. (2010, p. 731) also suggest that, 'collaborative writing through a Deleuzian lens seeks to cultivate the in-between, not the points, the ends.'

\section{Post-Qualitative Inquiry}

There is a growing body of qualitative research into supervision pedagogy that examines the doctoral relationship as a significant aspect of identity formation for both students and supervisors in the process of becoming an academic (Barnacle, 2005; Green, 2005; Halse \& Bansel, 2012). This research has importantly explored supervision as a lived, intersubjective relation through autoethnographic writing by supervisors, students themselves, and less often through both voices (Bartlett \& Mercer, 2000; Lee, Blackmore \& Seal, 2013). However, our paper moves in a different direction as we situate our research approach within post-qualitative inquiry (Kuby et al., 2016; Lather, 2013; St Pierre, 2012) where our theoretical analysis is informed by post-humanism and new materialist ontologies (Braidotti, 2013). We are less interested in the humanist quest to discover the meaning of doctoral experiences 'within' the supervisor and/or student as an agentic subject, and more interested in the transformative potential of collaborative writing as a research practice to 'map connectives' that shape and disrupt our experiences (Gannon, 2006; Mazzei, 2013; Phillips \& Larson, 2013).

Drawing upon insights from post-humanist and feminist theories we explore supervision as a relational process of entangled knowledge creation (learningunlearning) that can be traced through desires to know and become academics. This process is, as Deleuze and Guattari (1987) suggest, bound up in an assemblage that produces desiring subjects through multiple flows of affect. Desire works through the forces of affect that are embodied, pre-personal intensities produced in relational to human and non-human others. As Hickey-Moody and Malin (2007, p. 8) state, affect is, 'that which is felt before it is thought; it has a visceral impact on the body before it is given subjective or emotive meaning. Thinking through affect brings the sensory capacity of the body to the fore.' The recognition of supervision as embodied and affective enables us to think about how the rhizomatic, or symbiotic relationship, moves students and supervisors in particular ways (closing down, opening up). In contrast to the metaphor of the supervision journey where academics guide students towards Knowledge, assemblage thinking draws our attention to the affective moments of disruption and connection that generate new lines of thought. In thinking about these co-constituting dynamics of supervision, Deleuze and Guattari (1987, p. 10) use the example of the orchid and the wasp to 
show how symbiotic movements enable each party to flourish, or alternately perish:

Wasp and orchid, as heterogeneous elements, form a rhizome...At the same time, something else entirely is going on: not imitation at all but a capture of code, surplus value of code, an increase in valence, a veritable becoming, a becoming-wasp of the orchid and a becoming-orchid of the wasp.

Rosi Braidotti's (2008, p. 4) feminist work also turns our attention to the question of an ethics of supervision that is produced through the movements of collaborative writing as a rhizomatic practice,

... affirmative ethical relations create possible forms of transformation of the negative by mobilizing resources that have been left untapped, including our desires and imagination. The affective forces are the driving energy that concretises in actual, material relations. These relations constitute a network, web or rhizome of interconnection with others.

This generative approach enables us to rethink supervision practices as productive of a 'relational becoming' where both students and supervisors learn and unlearn, engage in knowing and importantly unknowing as an on-going process. We hold the creative and critical in tension through awareness of the hierarchical power relations that govern our student-supervisor subject positions within the globalised, neoliberal networks of higher education. Collaborative writing enables us to transgress the normalcy that rests upon a fantasy of rational subjecthood (where doctoral learning progresses from $\mathrm{A}$ to $\mathrm{Z}$ ) as we become entangled in the complex affects that move and write us through new lines of rhizomatic thought (Kuby et al., 2016). The following section turns to the approach that we have used in our analysis of the affects produced by 'critical moments' - where we as supervisorstudent/s stalled, became stuck in past patterns governed by unhelpful expectations, and then found our way through.

\section{Collaborative (re)Writing Critical Moments}

Taylor's (2011) humanist person-centred approach to supervision has emphasised the value of reflection on the $\mathrm{PhD}$ experience through reference to Miles and Huberman's (1994, p. 115 as quoted in Taylor 2011, p. 6) notion of 'critical incidents.' Such moments are significant events that are 'seen as critical, influential, or decisive' in the construction of individual meaning. This approach to reflection has been taken up by $\mathrm{PhD}$ students who have produced narrative accounts of their own 'turning points or on-going challenges' in the research journey (Lee, Blackmore \& Seal, 2013, p. 3). The related concept of 'critical 
moments' was conceptualised by Henderson, Holland, McGrellis, Sharpe, and Thomson (2007, p. 20-21) to describe events and situations that, while perhaps not deemed 'critical' at the time, are in hindsight recognised as significant. We take up this focus on critical moments through the materialist turn to writing, particularly acknowledging the intersecting traditions of collaborative writing and post-structural readings of feminist memory work (Claiborne, Cornforth, Crocket, \& Manathunga, 2013). Through our writing-remembering we mobilise a different ethical practice that reworks the personal experience in critical moments to reveal the shared uncertainties, embodied affects and creative possibilities. As Braidotti (2008, p. 12) suggests, "Affirmative ethics is not about the avoidance of pain, but rather about transcending the resignation and passivity that ensue from being hurt, lost and dispossessed.'

We contend that a relational approach not only works to foreground power as productive of (self-other) knowledge, but also affords the opportunity for understanding how subject positionings and normative truths can be disrupted. In this way we embraced multiplicity by sharing individual writing fragments between supervisor and student, as well as between students themselves. The many perspectives and positions from which we speak help to break down the individualised nature of the relationship that can lead to supervisors or students blaming themselves (or each other) when the process becomes stuck. Rather, by appreciating the entanglement of new, creative and improvised practices of writing our experiences we have revealed the affects and practices through which supervisor-students learn from each other in dynamic relation. Like Kuby et al. (2016, p. 141), 'we are interested instead in emergences, the forces of becoming as teachers/students teach $\leftrightarrow$ learn from/to/with each other.'

Kuby et al. (2016, p. 141) seek to make visible the 'tensions and possibilities of teaching $\leftrightarrow$ learning.' To do this they advance the notion of 'rhizomatic pedagogy,' defined as 'pedagogy that embraces uncertainties and departures' (p. 141). In a similar way our work thinks with theory, in particular Deleuze and Guattari's (1987) 'rhizome' as a driving force for their writing. In contrast with the more linear structure of a tree, the rhizome has certain qualities, namely, a) 'any point of a rhizome can be connected to anything other, and must be' (p. 5), b) multiplicities are rhizomatic, 'a multiplicity has neither subject nor object, only determinations, magnitudes, and dimensions that cannot increase in number without the multiplicity changing in nature' (p. 8), c) 'a rhizome may be broken, shattered at a given spot, but it will start up again on one of its old lines, or on new lines' (p. 8), and d) the figure of the rhizome is 'a map and not a tracing' (p. 12), 'it is a stranger to any idea of genetic axis of deep structure' (p. 11). The figure of the rhizome allows us to think about our collaborative e-writing practices in ways that open up what the doctoral supervision relationship might look like, what it might feel like, and, importantly, what it can $d o$ in shaping future possibilities. 
As Gannon (2006) has argued, writing about one's self is always mediated by relations with others and the language through which we perform contradictory subject positions and embodied affects. As such our writing offers partial knowledge and our intention is not to identify the 'truths' of successful supervision or doctoral experience, rather it is to reveal how dilemmas can be negotiated in ways that develop academic know-how. In writing both the students' and the supervisor's accounts side by side we make visible key moments where blame, failure and frustration might be reworked from negativity to more generative possibilities.

Our method involved writing on a shared, but closed, online forum about our experiences of supervision over several months (throughout 2012) as both students approached the final phase of their doctorates. The online forum was originally established as a means of sharing ideas, resources and providing support during particularly challenging points in the process. The desire to write emerged out of the face-to-face discussion group that met regularly throughout the year with a larger group of students. Our collaborative writing analysis was undertaken after both students had graduated (in 2013) and were starting to supervise students themselves. It involved writing, remembering, reading and rewriting our texts in relation to each other that produced 'the enfolding of past and future into the moments of the entangled becoming-writing' (Phillips \& Larson, 2013, p. 735). Our analysis has been informed by Deleuze and Guattari's (1987, p. 4) notion of 'plugging in' theory where by we read-write our text through analytic questions that trouble the relations of governing-improvising and (not)knowing in becoming a learning alliance (see also Jackson and Mazzei, 2013). Our written fragments are materialist, embodied through multiple relations of affect (fear, shame, pleasure) that were remembered-reworked through critical moments that connected and separated us at the same time. Written as a juxtaposition of voices and texts (eforum extracts, academic text), with loosely interconnected threads and capitalised Truth relations, we occupy the in-between of knowing-unknowing. This writingremembering moved us to think our way through the conditions of possibility for collaboration, as Deleuze (1995, p. 141) captures, 'a spark can flash and break out of language itself, to make us see and think what was lying in the shadow around the words, things we were hardly aware existed.'

\section{Supervision as Governing and Improvising}

The tensions that govern the experiences of supervisors and students within higher education have been the subject of critical debate regarding the need to situate pedagogical challenges within the institutional and social contexts of advanced liberalism (Halse, 2011; Halse \& Bansel, 2012; Manathunga \& Goozée, 2007). Students are required to complete high quality research within tight time frames that are governed by funding and policy regimes within the market economy of higher education. Supervisors are expected to ensure the quality of $\mathrm{PhD}$ 'outputs' 
and are subject to new audit practices that regulate professional development, require more administration and are often instrumental in focus. There now exist a multitude of workshops, recipes and tips for successful supervision that, while well intentioned in the desire to improve the capabilities of supervisors, often fail to address the complexity of the pedagogical relationship. Despite the changing institutional networks and power relations that have come to govern the conduct of universities, and by extension supervisors, the model of supervision pedagogy remains a highly individualised relationship where expert advice is given and received (Halse \& Bansel, 2012). As Manathunga (2005, p. 17) has argued, this intensification of supervision as a 'privatised sphere' of academic life undermines the 'relational' understanding of knowledge creation and collaboration that can offer different conceptualisations and practices. Yet, tensions also give rise to different desires that we often hear little about in terms of the possibilities for supervising otherwise.

Halse and Bansel (2012, p. 378) make the case for a more relational ethics that would enable praxis in doctoral supervision through the creation of a 'learning alliance.' In contrast to the normative models of supervision (apprenticeship, person-centred, scientific-technical and sociocultural) they argue for a pedagogy informed by shared practices, policies and processes that connect individuals and organisations. The emphasis placed upon moral responsibility within the learning alliance does reconceptualise the university as existing beyond the market economy. However, 'responsibility' can discursively position supervisors as central actors when they often cannot exercise power to shift policies at the national or institutional level that affect workloads. Through our post-qualitative inquiry we explore the possibilities of a learning alliance (defined as the connection between two distinct humanist subjects) that is an entanglement of self and other, disrupting normative practices and supervisor/student binaries (Claiborne et al., 2013). We write through the affects that are produced against the normative ideal of the rational, autonomous, self-governing supervisor who moves students through their doctoral education as efficiently as possible.

SF: Numbed from sitting through another 'compulsory' supervision workshop to tick the box for effective 'skill' acquisition, my mind drifts to considering how this training space privileges reflective minds over affective bodies (the 'top tips' for success) in the institutional desire for 'timely completions.' Throughout the workshop the affective entanglements that produced supervision relations gave rise to murmurings, disrupting and unsettling those orderly pedagogic conversations academics wrestled with their own (remembered) experiences as, and with, students (fears of failure, isolation, uncertainty).

I'm still feeling troubled by the omission of the complexities that are bound up with the supervision experience. Drinking coffee together outside in our doctoral reading group, we enjoy being away from the normative confines of the office. The warm summer morning is loosening up our ideas. Talk turns to our frustrations 
with student and supervisor 'training.' We open up uncharted territory between us. These conversations begin to unravel what we think we 'know' about our studentsupervisor relations. Moving into the messy nature of learning to 'do' a doctorate or become a supervisor, troubling experiences bubble up for some and burst out for others. These dynamic affects are '(re)writing' me and our pedagogic subjectivities in ways that take time to fathom.

There is no return to our previous selves; collective talk transforms into writing that is singular and multiple. We are typing through the tensions: fingers on keyboards hesitate with pensive thoughts. Stretching a stiff neck, urgent typing, editing around uncertainty, waves of relief - words are out there, shared in this liminal space that is full of possibility. The e-forum draws us into a digital assemblage of lively data that plays out through words and bodies - that transforms our alliance (Lupton, 2016).

\section{On 'Not' Knowing: Uncertain Affects}

Learning alliances are complicated by power-knowledge relations of different kinds. It is not uncommon for supervisors to become caught in normative (historically masculine) heroic constructions of leadership (as all Knowing subjects) as these notions circulate through universities and amongst students who invest their desire for knowledge in credible leaders (to know what they know, to be like them) (Lee $\&$ Green, 2009). Inger Mewburn, in her blog The Thesis Whisperer, regularly posts on the challenging relationship between supervisor and student and the expectations that come with it, and provides different ways of thinking about how to 'manage' this kind of relationship. In a recent blog post (The Thesis Whisperer, 8 April, 2015), she discusses the common misunderstanding of the supervisor as a 'superhero'. She provides a checklist of things a supervisor needs to be able to perform, yet acknowledges that it is impossible for a single person to be able to know everything; being a supervisor - 'you never really master it. There is always something new to learn.' In a study of 100 blogs written by academics, Mewburn and Thomson (2013) also found that 'supervision' was one of the common themes discussed. The challenges faced by both supervisors and students were identified as similar across most disciplines, particularly in relation to the broader context of academic work conditions.

There are familial metaphors that complicate supervisory relations for women as we navigate through historically masculine terrain with few signposts about how we make sense of supervision as a gendered practice. Bartlett and Mercer (2000) have identified the gendered effects (and affects) of mother-daughter expectations that can mediate how guidance is provided and received. However, heroic and familial discourses work against the conditions that are necessary for women students to exercise power through their writing voice and they undermine the creation of learning alliances. Supervisors must account for the resources and time taken to complete a $\mathrm{PhD}$, as well as the quality and ethics of the project. In this 
context of 'responsibility' women supervisors must negotiate the changing relations of proximity and distance, while enacting an ethics of care and enabling the exercise of intellectual autonomy in others (Claiborne, 2013). We write through these tensions arising from our expectations of each other to perform as competent, autonomous, intelligent women - norms that also produce the uncertainty of 'not knowing' enough.

SF: We have been working through the first whole thesis draft in my office, talking about the Conceptual threads that need to connect the Argument and how to deepen the Analysis. It is intense as I raise the intellectual bar a little higher, we need to move things to the next level. I think you are ready for this now but this step is always a little risky. Across the table I see lots of nodding, murmurs of agreement about different theoretical points, a few frowns and then a confident exit from my office Task list in hand.

RS: I'm lost, I have no idea what she's talking about... somewhere between power relations and organisational practices I seem to have lost the plot. 20 minutes into the meeting and I'm already brain dead. What does she Mean? I've stopped taking notes, maybe she'll figure out that I'm lost?! No, she just keeps going and I keep nodding my head, pretending to Understand everything. I have that feeling of Guilt creeping up again...

I'm supposed to Know all this (to be more like Her), we've already discussed some of those issues in the last meeting. I should've gone back to my notes from the last meeting. Maybe I should ask for some suggestions on further readings? It usually helps to read through a few things after the meeting so that I can start making the connections... but then again, we've discussed this before... no, I don't want to look stupid... But I do need to know where to go from here...?! I wish I knew how to ask the Right Question.

AP: During supervision I would sit and listen and think to myself: how am I ever going to Grasp all that She is saying. Then I would go away, and the next day look at my notes and pick out each point - it might be about a theorist, or concept, or other links. I would follow it up, reading and writing, and hoping that what I was doing was 'enough.' It never felt like enough. The words that she spoke during our supervision sessions seemed far removed from what I eventually wrote down. But each time I would then show her my next version of the writing, she always seemed to think that I had improved the work to some extent. As I went through the process - email through writing, meet in her office, sit down and take notes furiously as she commented on my work and the ideas she thought connected. I became more confident in my ability to pick up the threads and weave them through. I began to understand that the reason it wasn't all 'clear' to me, was because the Ideas were complex, 'difficult,' but compelling. It was up to me to follow them up, not up to her to explain them to me in simple terms.

SF: It was at our discussion group that someone let slip, 'Yeah sometimes I come out of your office feeling more confused than when I went in!'. There is 
laughter all round, you all nod with a shared understanding that I have only just arrived at. Multiple supervision sessions flash through my mind. Really? Why have I not grasped this before? I think I am approachable, why can't you Say something? You all reply, 'well sometimes we don't Know what to say or what to ask.' This moment strikes a profound chord for me about the desire for selfcertainty in knowledge and the struggle to articulate 'not' Knowing. My own 'knowing' about supervision unravels.

How to think and talk 'with' each of you about what you do and don't understand in a way that brings ideas alive? Let's try out a few different techniques; comment on the draft that you give me (what you feel is clear, what is woolly), break things down, note the connections between ideas. We adopted these practices more explicitly and they seemed to work, we spent less time with me Explaining and more time with you reflecting, working things out and leadingteaching me as we went. I never again assume a nod means I Know.

Without some sense of shared insight into the relational process we can end up in a dead end of frustration, misunderstanding and self-doubt. Supervisors don't make it easy for students to tell us when they are struggling; we expect that their diligence, dedication and perseverance will get them over the line. High achieving students respond by trying very hard to perform competently, to perfect their understanding. Yet, supervisors need to know when things slip otherwise we find ourselves in the spiral of misunderstanding; repeating points over and over, wondering why progress has stalled. We will need to refuse, but not deny, the status hierarchies and power relations that underpin the subject positions of The Supervisor and The Student. We are not self-present subjects and like all relationships, we have blind spots on both sides and complex levels of communication that simultaneously involve developing a trusting and challenging relationship (is she hearing my concerns about the work rather than her ability?), mastering content (have I been clear enough? does she 'get' what to do next?) and developing academic practices (does she know how to do this?). Collaborative writing - like this paper, and others we have written together - locates us in those moments when ideals of perfection unravel so we can move beyond the stifling expectation that understanding 'should' come easily. These moments of insight are often unexpected and we have had to (un)learn through writing those 'critical moments' together.

\section{(Un)learning and Improvising Practices}

Grant (2005, p. 1) has aptly framed supervision pedagogy as a continual 'practice of improvisation.' Engaging in critical discussion about the expectations that govern supervisor and student identities is a moment of improvisation that can produce different ways of working together with more helpful supervision practices. Australian citizens' tuition for $\mathrm{PhD}$ study is paid for by the government, and many International students are offered a scholarship to cover tuition and often a living 
allowance, thereby positioning $\mathrm{PhD}$ students are investments in the neoliberal university. As investments, students and supervisors are expected (via checklists and policy requirements) and supported to perform in certain ways. Fitzpatrick and Fitzpatrick (2015, p. 51) explore the use of poetry to shift supervisory relations as 'improvisation in research dialogue can contain a productive and creative fragility, requiring vulnerability from both parties.' Writing about unlearning to be Supervisor and Student we explored the techniques, practices and moments of undoing through which we improvised. We did not always know at the time that such improvisations were working for us as we wrestled with a range of affects (uncertainty, fear and pleasure, excitement) - through collaborative writing they became intelligible in ways that moved us to know differently.

AP: Sometimes I did leave her office in a spin, but for me it was all part of the process of undoing and unlearning what I thought I knew. Starting to read feminist post-structural ideas was not an easy move. So she couldn't give me 'the Answer,' but she helped me find a way to think (and write) about the issues I was tackling in my Thesis. She would offer books and articles to read, and I would wrestle with these in my writing - in a writing journal. Some of these ideas ended up in my thesis. I also decided to write down all those doubts, concerns and 'fantastic' insights. If I had an idea as I was reading, I'd write it down in a purpose made word document - rather than talk about it as I often would in the past. I wrote them down, shared them at our meetings, came and used the feedback to refine my ideas. I tried different ways of reading too: on the couch, outside, at my desk, at the kitchen bench. Insights came at different times and a change of material setting was sometimes just what was needed.

RS: I think what struck me the most about her style of supervision is that she really tried to make things work for me and to understand 'how I work' and my way of 'doing things.' I can reflect on what I am doing and why, to identify my strengths and use those strengths to get things done. I've moved my life here from Austria to do this research and nothing is familiar anymore. I want Structure, I like to have a Plan, I need Deadlines. She has always helped me to set realistic targets, then asked me to send through a summary of what we discussed in the meeting and what the next 3 steps would be. That sort of plan works for me. It helped me keep track of everything, keep things organised - just the way I like it. But I don't always like it...

I try to smile as I get up to leave her office. Wow, that was intense! We have worked through the first full draft of my thesis and my head is spinning. I feel like I need to rewrite the whole thing... where to start?! Before I leave, I ask when we should meet again and what part I should rework first. She says, 'let's just play it by ear. See how you go.' This doesn't work for me. Doesn't she get that I need a new Deadline? I want to start with chapter 4, have a new draft of that chapter by a certain date. I try again... 'So if I rework that chapter next week, can I send through a new draft on Friday?' (Am I driving her crazy? Am I asking too much? I know she is really busy at the moment...) 
Knowing how overwhelmed I am with all the ideas we have just discussed, she explains: 'Don't push yourself too hard. Take your time. Maybe spend a week just Thinking about all these Ideas before you go back and rework chapter 4. Draw a few mind maps... whatever works for you. But no writing for a week!' Sure... I nod and take off. Really?! No writing at all? That's not going to work for me. I need to Produce something! I'm disappointed. I thought she knew what worked for me and what doesn't. Why does she want me to do that?? I need to go to dance class to escape, the walls and words are closing in on me.

(two days later) I've decided to give it a go. Maybe there is something important she wants me to learn from this exercise, which I can't see yet?! I'm sure there is. So here I am sitting at my desk, 'Thinking'... I check my emails instead. I update my Facebook profile. I have a coffee with my friend.... I run into SF in the lunch room. She asks me how my 'Thinking' is going. I roll my eyes... 'It's driving me crazy. I am getting nowhere.' Again, she reminds me to 'be patient, it will come.' Yeah... right...

(a week later) Fidgeting on my chair I've tried to draw a mind map. Not my thing. I feel like I haven't done anything all week. Really, what's the point of just sitting here in this stuffy office, 'Thinking'?! I go back to my table of contents and start restructuring. Yes, that's more like my thing... I reread my chapters as well as one of the articles that seems important for what I am trying to do. And all of a sudden - of course!! It all makes sense now! I can see it. I know what I have to do. Why didn't I see it earlier? It's so obvious. And just like that I am back on track... I realised later that the whole point of this exercise was to learn how to step back and think in different ways about my writing. Rather than her telling me what to do and how to Fix my chapter, I learned how to read my own draft and to see the connections. I was pretty frustrated at the time, but I now appreciate the process. Now I quite often deliberately take these 'no Writing, just thinking' breaks and I like to think that because of that, my writing has improved a lot since then.

\section{Unexpected Material Relations}

What is often missing or invisible in the literature and discussions of doctoral supervision are the material relations that are not about the thesis, but are about the contexts beyond that sustain scholarship. These contexts and relations include campus spaces, libraries, cafes, common lunch rooms, shared offices along with home, leisure and social relations that are often invisible to supervisors. Yet, these material relations emerged as important in the creation of a learning alliance that recognised embodiment and affect as productive rather than peripheral (Lee, Blackmore \& Seal, 2013).

AP: At times I become stuck. She suggests going for a walk. She says that this is no less useful than sitting in front of a computer screen 'Thinking' about the areas of the Thesis I have become 'stuck' at. I am confused about how going for a 
walk might help me. But I do it. I am a 'Good' Student. I listen and take her advice. I go for a walk. I don't think about the Ideas in the Thesis, but somehow it helps. I sit down to write and get a new angle, a new idea. 'Its probably off track, but it's something'. Writing, moving, doing. I know that she runs. So I go from walking to running. That seems to help too.

SF: I think one of the challenges is to learn to value your work from multiple perspectives - my view, your own view and views of others/peers. Given the individualised nature of the $\mathrm{PhD}$ (RS's point about the pressure to do it all by myself) I think it is so important that you have each other to bounce ideas off, vent about the frustrations and think your way through - because really no-one can tell you how to do it. And humour helps so much and you all use humour in ways that helps to open up a space to respond differently to whatever is going on.

RS: M came in to have a chat about her methodology chapter. She showed me the table of contents and wanted to know if it made sense. I think I said something like, 'well if you start with that, then you can add a bit about this here, move that section to the second part of the chapter, and then you can come back to all this in the final section...' The Structure was clear - well to me anyway. The funny thing, however, was that I also added 'remember, M, you need to take the reader on a journey!' She looked at me and said 'whoa, you just sounded like her. That's EXACTLY what she would say.' We both laughed and started joking about getting $\mathrm{t}$-shirts printed saying 'Remember, you need to take the reader on a journey $-\mathrm{SF}$, 2013.'

AP: Who knew poststructuralist theory could be fun! I would go to our 'reading group' in the beginning, full of trepidation and uncertainty and she would use humour to work through ideas. As a group we'd laugh at some of our insights, interpretations and understandings. But not in a demoralising way. It was the excitement of understanding, of synthesis, of working through complex ideas in meaningful ways. There was a strong sense of belonging - as a group of women situated in a Business School, we were outlaws in some ways...I remember the first reading group I went to. The reading was a chapter from John Law's After Method. I was excited by the possibilities and piped in with my understanding of the reading. After the group one of the more advanced $\mathrm{PhD}$ students took me aside and said, 'you did great.' Her comment confused me. Weren't we just discussing ideas?

\section{Becoming, Supervising, Improvising}

Deleuze and Guattari's (1987) notion of enfolding provides a useful way to think about the process of becoming whereby supervisors are continually learning as they enfold the external forces of the present (institutional demands about completion, instrumental relations) and their own embodied histories as students. An insightful study by Lee and Williams (1999) identified how supervisors have a tendency to reproduce the approach that their own supervisor employed despite the difficulties 
(and frequently the trauma) that they experienced (and despite the different institutional challenges of the contemporary university). The need for ethical responsiveness about the limits and possibilities of the supervision relationship is evident in terms of the many forces that come into play - the influence of one's own (negative) supervisory experiences as well as the mediating effects of historical or contemporary norms (Halse, 2011; Manathunga \& Goozée, 2007). We revisited our e-forum some time after both RS \& AP had graduated and moved into their first supervision roles, to explore the on-going need to think otherwise.

SF: I hope these comments help counter the 'supervisor pedestal' that gets in the way. I can honestly say that I felt all the things that you have mentioned as a $\mathrm{PhD}$ student too. With the completed $\mathrm{PhD}$ as 'Evidence' you can do it, the angst and uncertainty dies down, but it can be productive beyond a personalised realm. Becoming a supervisor involves multiple, intense relations to manage with students, compared with being a student who is invested mostly in one primary connection. Because of the affects involved there need to be points of differentiation or 'boundaries' (some supervisors remain disengaged all the way and others have no sense of the student as a separate being with their own thoughts and lives).

It is easy to 'burn out' with the other demands on our time and not be very useful supervisors. What is so different as a supervisor is the necessity to manage the process that is often overwhelming for students who cannot yet see what they can Accomplish. I'm not a therapist or a boss, nor a parent nor a friend in the conventional sense, so it is a hard relationship to make explicit and mutually understood. It is also a gendered context and women generally expect more of each other.

AP: Working with my first student and co-supervisor I enjoy our meetings. 'Your contribution is great', says the Principal Supervisor (the more senior academic who asked me to join the team). I secretly (or not so secretly) beam. What a feeling! To be mentoring and providing support and guidance to a student. I guess it's a fine line between being supportive and second guessing the student though. Am I overdoing it? I still have a lot to learn and I am sure that every student I supervise will be different, facing different challenges, both personally and intellectually. But the first lesson seems learnt - that a relational approach is key. If my student doesn't understand something, it's not all their 'fault,' nor is it all my 'fault'; instead we can both play an active role. We are allies and have something to learn from each other. I mean, that's what attracted me to academic work in the first place; a love of learning and sharing ideas.

RS: Moving to another new country with my first job I take on my first supervision role wondering how it will go. I have another meeting with 'Katie'... I am struggling with this one. I feel like we are running around in circles. She's got too many things on her plate, doesn't seem to be focused on her dissertation. Why can't she be more like 'Steve'? Steve sends through an email summary after every meeting, he has an action plan and he has already put the next three supervisor meetings in his diary - and so have I. He seems to be on track. But maybe he's 
not?! How can I be sure? Just because we have a similar way of working doesn't mean he's not facing any challenges, I remind myself. How do I know if he's struggling when he doesn't tell me? Oh wait... this meeting is about Katie... Right, how can I help her to prioritise and focus on her $\mathrm{PhD}$ for once? I pause and think... we're in this together. We need to find a way that works for both of us. I can't help but ask myself, what would SF do?

AP and RS: Becoming supervisors we have learnt to trust our students, to have confidence in their abilities, to provide suggestions where appropriate, to celebrate milestones and achievements, and to laugh together. And also to have boundaries, to stick to meeting times, to reply to emails in a timely and thoughtful manner, to highlight strengths and appreciate what they bring. We are no experts, though we can make suggestions. Thinking through the moments we became 'stuck' and 'unstuck' has helped identify the relational context that shaped what worked and what didn't. Using humour. Moving, walking, running, dancing. Writing more, talking in different ways. Questioning normative expectations. Reading, for enjoyment as much as 'usefulness.' Connecting with others. Finding synergies. Getting excited. Trying out new technologies, social media, software to experiment with writing alone-together. These are not aspects of the supervisory relationship that are 'taught' in professional development seminars and programs.

Our collaborative writing has enabled us to make known and reconfigure the unspoken norms that governed our interactions as 'good' doctoral students and supervisor. The critical moments that we have identified generated for us new insights into the relational process that in turn enabled AP and RS as new academics to become open, 'improvising' supervisors themselves. In writing through our supervisory experiences we have identified the significance of understanding how the dynamics of affect play out for students and supervisors through power relations oriented around perfectionism, individualised notions of academic work and lead to forms of self-government that perpetuate uncertainty.

Students can become trapped in the isolating performance of autonomy, while supervisors can remain (knowingly or unknowingly) distanced on a pedestal that prevents honest engagement with learning. Hence, we have found that one useful strategy is to develop a shared language through which to articulate the embodied, affective and relational notion of a learning alliance - talking about uncertainty and understanding the entangled process of becoming (Halse \& Bansel, 2012; Phillips $\&$ Larson, 2013). Framing questions through a generative ethos (Braidotti, 2008) is also central to the creation of different desires for knowledge beyond Truth and self-certainty - what practices work best for your learning (writing, analysis)? What is getting in the way? What can you 'do' differently now? What are the best material environments for learning? In addition, students and supervisors benefit from collective understanding and shared humour as a means of contesting the individualisation of blame (on self or others) as well as the creation of collaborative cultures of improvisation - what worked for you may or may not work for me. We have outlined the different analytic practices that we deployed through our focus on 
'doing' doctoral supervision (from self management, email summaries, knowing one's own style, for example, structure, plans, drafting), reading one's work and finding what works for writing, (or not writing). Sharing know-how collectively also helps to develop different academic voices and flexible ways of writing/ speaking ideas in progress (writing for supervisors, self and others, reading/ discussing ideas collectively, using Google groups and Facebook). In this way the doctoral experience becomes embedded within rhizomatic thinking (Kuby et al., 2016) that moves through the practices of sharing, speaking, revising and reinhabiting writing. Although the single goal remains - completion and conferral of the $\mathrm{PhD}$ - there are multiple routes and possibilities along the way.

Guidelines about 'effective supervision' are often highly prescribed (in 'to do' lists) and without acknowledging the importance of reflexive practice they risk perpetuating many unhelpful norms. As Kuby et al. (2016, p. 144) state, 'Transgressive practices risk normalization when they become prescriptive, or procedural.' Rather than propose a new set of 'best practice' points we suggest that supervisor training and student induction could embrace the idea of improvisation and writing through the affective, embodied materiality of critical moments (failures and uncertainties as well as insights and successes). However, these conversations need to be embedded within an institutional culture that supports a relational approach, the use of solution focussed thinking and appreciative modes of inquiry (Cojocaru, 2010; Manathunga \& Goozée, 2007). Fostering an appreciative vision (Cojocaru, 2010) and affirmative ethics (Braidotti, 2013) in supervisor training could help shift entrenched ideas about student problems (cultures of blame) and create a collective space for thinking about 'the relational.' Our collaborative writing approach seeks to open up pedagogic debates beyond the humanist notion of 'student centred' learning to embrace the transgressive possibilities of post-qualitative inquiry where knowledge is produced through the in-between spaces (self-other, self-computer, self-otherness, self-world) that have previously been forgotten, denied.

Moments of being 'stuck' can be refigured. Instead of crisis and fear of failure, these moments can be vital points where new lines of flight take off. When broken or shattered, a rhizome will start up again - either following 'old lines, or on new lines' (Deleuze \& Guattari, 1987, p. 8). The figure of the rhizome has enabled us to reflect on our writing and see the possibilities inherent in moments of 'being stuck.' Thinking through the PhD supervision process as rhizomic pedagogy (Kuby et al., 2016) we turn away from any model that positions the process as structural or generative in a linear form (Deleuze \& Guattari, 1987). Instead, through our collaborative writing we have made visible the multiplicity of doctoral supervision - what works for some, won't work for others, what worked then might not work now. Much like Nancy (in Kuby et al., 2016, p. 144) we all - students and supervisor - were becoming "more aware of the demands, less afraid of them, and clearer about divergences.' This allowed us to move forward with our research, despite uncertainty, fear, and sometimes 'getting stuck.' 


\section{Acknowledgements}

We would particularly like to thank the anonymous reviewers of our article who provided insightful comments that were very helpful for thinking otherwise. We would also like to acknowledge the early contributions to our eforum by Mandi Baker who was completing her $\mathrm{PhD}$ at the time.

\section{REFERENCES}

Barnacle, R. (2005). Research education ontologies: exploring doctoral becoming. Higher Education Research \& Development, 24(2), 179-188.

Bartlett, A., \& Mercer, G. (2000). Reconceptualising discourses of power in postgraduate pedagogies. Teaching in Higher Education, 5(2), 195-204.

Benade, L. (2015). Postgraduate research supervision as a partnership in the context of Freire's dialogical pedagogy. Knowledge Cultures, 3(5), 102-102.

Braidotti, R. (2008). Affirmation, pain and empowerment. Asian Journal of Women's Studies, 14(3), 7-36.

Braidotti, R. (2013). The posthuman. Cambridge: Polity Press.

Claiborne, L. B. (2013). When doctoral students struggle to make progress: supervisors' reflexive exploration of ethical challenges. Knowledge Cultures, 1(5), 102-120.

Claiborne, L. B., Cornforth, S., Crocket, K., \& Manathunga, C. (2013). Exploring ethical difficulties in doctoral supervision: reflexive collaborative theorising around memory and practice. Knowledge Cultures, 1(5), 39-49.

Cojocaru, S. (2010). Appreciative supervision in social work: New opportunities for changing the social work practice. Revista de Cercetare şi Intervenţie Socială, 29, 72 91.

Connell, R., \& Manathunga, C. (2012). On doctoral education: How to supervise a PhD, 1985-2011. Australian Universities' Review, 54(1), 5-9.

Deleuze, G. (1995). Negotiations 1972-1990 (M. Joughin, Trans.). New York: Columbia University Press.

Deleuze, G., \& Guattari, F. (1987). A thousand plateaus: Capitalism and schizophrenia. Minneapolis: University of Minnesota Press.

Fitzpatrick, E., \& Fitzpatrick, K. (2015). Disturbing the divide poetry as improvisation to disorder power relationships in research supervision. Qualitative Inquiry, 12(1), 50-58.

Fox, A., \& Allan, J. (2014). Doing reflexivity: moments of unbecoming and becoming. International Journal of Research \& Method in Education, 37(1), 101-112.

Freire, P. (1998). The adult literacy process as cultural action for freedom. Harvard Educational Review, 68(4), 480-498.

Gannon, S. (2006). The (im)possibilities of writing the self-writing: French poststructural theory and autoethnography. Cultural Studies $\leftrightarrow$ Critical Methodologies, 6(4), 474-495.

Grant, B. M. (2005). The pedagogy of graduate supervision: Figuring the relations between supervisor and student. PhD diss., ResearchSpace@ Auckland.

Green, B. (2005). Unfinished business: Subjectivity and supervision. Higher Education Research \& Development, 24(2), 151-163.

Halse, C. (2011). 'Becoming a supervisor': the impact of doctoral supervision on supervisors' learning. Studies in Higher Education, 36(5), 557-570.

Halse, C., \& Bansel, P. (2012). The learning alliance: ethics in doctoral supervision. Oxford Review of Education, 38(4), 377-392. 
Henderson, S., Holland, J., McGrellis, S., Sharpe, S., \& Thomson, R. (2007). Inventing adulthoods: A biographical approach to youth transitions. London, Thousand Oaks, New Delhi: SAGE Publications.

Hickey-Moody, A. \& Malins, P. (2007). Deleuzian encounters: Studies in contemporary social issues. Basingstoke, UK: Palgrave.

Jackson, A. Y., \& Mazzei, L. A. (2013). Plugging one text into another thinking with theory in qualitative research. Qualitative Inquiry, 19(4), 261-271.

Kuby, C. R., Aguayo, R. C., Holloway, N., Mulligan, J., Shear, S. B., \& Ward, A. (2016). Teaching, troubling, transgressing: Thinking with theory in a post-qualitative inquiry course. Qualitative Inquiry, 22(2), 140-148.

Lather, P. (2013). Methodology-21: What do we do in the afterward? International Journal of Qualitative Studies in Education, 26(6), 634-645.

Lather, P., \& St. Pierre, E. A. (2013). Post-qualitative research. International Journal of Qualitative Studies in Education, 26(6), 629-633.

Lee, A., \& Williams, C. (1999). Forged in fire: Narratives of trauma in postgraduate research education. Southern Review, 32(1), 6-26.

Lee, A., \& Green, B. (2009). Supervision as metaphor. Studies in Higher Education, 34(6), 615-630.

Lee, E., Blackmore, C., \& Seal, E. (2013). Research journeys: A collection of narratives of the doctoral experience. Cambridge: Cambridge Scholars Publishing.

Lenz Taguchi, H. (2013). 'Becoming molecular girl': transforming subjectivities in collaborative doctoral research studies as micro-politics in the academy. International Journal of Qualitative Studies in Education, 26(9), 1101-1116.

Lupton, D. (2016). Digital companion species and eating data: Implications for theorising digital data-human assemblages. Big Data \& Society, 3(1), 1-5.

Manathunga, C. (2005). The development of research supervision: 'Turning the light on a private space.' International Journal for Academic Development, 10(1), 17-30.

Manathunga, C., \& Goozée, J. (2007). Challenging the dual assumption of the 'always/already' autonomous student and effective supervisor. Teaching in Higher Education, 12(3), 309-322.

Mazzei, L. A. (2013). A voice without organs: interviewing in posthumanist research. International Journal of Qualitative Studies in Education, 26(6), 732-740.

Mewburn, I. (2015). The Thesis Whisperer. Blog: http://thesiswhisperer.com/ (Accessed 03 June, 2015).

Mewburn, I., \& Thomson, P. (2013). Why do academics blog? An analysis of audiences, purposes and challenges. Studies in Higher Education, 38(8), 1105-1119.

Phillips, D. K., \& Larson, M. L. (2013). The teacher-student writing conference reimaged: entangled becoming-writing conferencing. Gender and Education, 25(6), 722-737.

St Pierre, E. A. S. (2012). Post qualitative research. In N. K. Denzin \& Y. S. Lincoln (Eds.), Collecting and interpreting qualitative materials (4th ed., pp. 447-480). London: SAGE.

Taylor, C.A. (2011). More than meets the eye: the use of video-narratives to facilitate doctoral students' reflexivity on their doctoral journeys. Studies in Higher Education, 36(4), 441-458.

Wyatt, J., Gale, K., Gannon, S., \& Davies, B. (2010). Deleuzian thought and collaborative writing: A play in four acts. Qualitative Inquiry, 16(9), 730-741. 
SIMONE FULLAGAR is Professor of Physical Culture, Sport and Health at the University of Bath, UK. As an interdisciplinary sociologist, she undertakes qualitative research into inequality and the embodiment of sport, leisure and health/mental practices. Simone has published widely using feminist theory and new materialism to explore women's depression and recovery, active living policy and alternative physical cultures. In 2015 Simone was awarded the Shaw-Mannell Award for Leisure Research by the University of Waterloo, Canada. She is currently working on a new book, Feminism and $a$ vital politics of depression and recovery (Palgrave, with W. O'Brien \& A. Pavlidis).

ADELE PAVLIDIS is an interdisciplinary sociologist working at the nexus of gender and leisure. Drawing on feminist perspectives of organisations, affect and emotion, and identity, Dr Pavlidis has published her work in internationally reputable journals in the fields of sport and leisure. Dr Pavlidis is the author of (with Simone Fullagar), Sport, gender \& power (Routledge) and is currently working on her second monograph, Feminism and a vital politics of depression and recovery (Palgrave, with S. Fullagar and W. O'Brien). Prior to completing her $\mathrm{PhD}$ Adele worked in the community sector as well as a short stint in the public sector.

RAPHAELA STADLER is a Senior Lecturer in Event Management at the University of Hertfordshire, U.K., where she teaches and researches festivals, events and their impacts on local communities and other stakeholders. Her PhD from Griffith University, Australia, investigated the issue of knowledge management and knowledge transfer within festival organizations. Raphaela has published work on knowledge transfer, community empowerment through festival participation, community cultural development, as well as the impact of event attendance upon family quality-of-life. She is currently involved in a research project on the value of group arts participation in improving the wellbeing of rural ageing populations. 
Reproduced with permission of copyright owner. Further reproduction prohibited without permission. 